\title{
Screening of attention deficit hyperactivity disorder in children aged 3 to 6
}

\section{years and 11 month olds of Tabriz, North-West of Iran}

Shahrokh Amiri ${ }^{1}$, Ayyoub Malek ${ }^{1}$, Homayoun Sadeghi-Bazargani2 ${ }^{2}$, Mona Mansouri ${ }^{1}$, Leila

Mehdizadeh Fanid ${ }^{3}$, Salman Abdi², Habibeh Barzegar ${ }^{1}$, and Ali Bahari Gharehgoz ${ }^{4}$

1. Research Center of Psychiatry and Behavioral Sciences, Tabriz University of Medical Sciences, Tabriz, Iran

2. Road Traffic Injury Research Center, Tabriz University of Medical Sciences, Tabriz, Iran

3. Department of Animal Biology, University of Tabriz, 29 Bahman Bolvard, Tabriz, Iran

4. Department of Psychology \& Education of Exceptional Children, University of Allameh Tabataba'i, Tehran,

\section{RESEARCH}

Please cite this paper as: Amiri S, Malek A, SadeghiBazargani $H$, Mansouri M, Fanid LM, Abdi S, Barzegar $H$, Gharehgoz AB. Screening of attention deficit hyperactivity disorder in children aged 3 to 6 years and 11 month olds of Tabriz, North-West of Iran. AMJ 2018;11(11):522-528. https://doi.org/10.21767/AMJ.2018.3530

Corresponding Author:

Leila Mehdizadeh Fanid

Department of Animal Biology, University of Tabriz, 29 Bahman Bolvard, Tabriz, Iran

Email: Ifanid@yahoo.co.uk

\section{ABSTRACT}

\section{Background}

ADHD (Attention deficit hyperactivity disorder) is a multifactorial disorder, defined by hyperactivity, impulsivity and attention deficits. Symptoms of ADHD begins during early childhood and negatively affects functionality at various levels.

\section{Aims}

This descriptive and cross-sectional study was conducted in 2016 to screen for Attention Deficit Hyperactivity Disorder in children aged 3 to 6 years, 11 months olds of Tabriz in Iran.

\section{Methods}

A total of 737 children aged 36 months to 6 years, 11 months in Tabriz were randomly selected from kindergarten and preschool centres. Both the Conners Early Childhood-
Parent and -Teacher forms were used to estimate the prevalence of ADHD.

Results

The results indicated that the prevalence of ADHD was 337 (45.7 per cent) based on Conners EC-Parent, 416 (56.4 per cent) according to Conners EC-Teacher, and 225 (30.5 per cent) based on the both Conners EC-Teacher \& Parent scales. The results of Fischer's exact test showed that the prevalence of ADHD in boys ( $n=117,35.3$ per cent) was significantly higher than that of the girls $(n=108,26.6$ per cent) $\left(p=0.01, x^{2}=6.57\right)$. The results of Chi-square test indicated that there was no difference among different age groups in terms of the prevalence of ADHD $\left(X^{2}=2.86\right.$, $p=0.41)$.

\section{Conclusion}

ADHD screening based on the Conners EC-Teacher \& Parent forms was estimated to be 30.5 per cent. The regional prevalence of ADHD appears to be greater among children under the age of 7, although the use of the new Conners EC tool in this study could have possibly affected the ADHD prevalence estimates.

\section{Key Words}

Prevalence, attention deficit hyperactivity disorder (ADHD), early childhood, preschool, kindergarten

\section{What this study adds:}

\section{What is known about this subject?}

There has been no study on the prevalence of ADHD in children aged 3 to 6 years, 11 months in Tabriz, Iran.

\section{What new information is offered in this study?}

The regional prevalence of ADHD appears to be greater among children under the age of 7 in Tabriz. 
3. What are the implications for research, policy, or practice?

The findings of this study emphasize the importance of ADHD screening in all kindergarten and preschool children for health interventions and promotion of social health.

\section{Background}

Childhood is a critical period in terms of establishing a psychological organization base. This period may also be associated with mental disorders, similar to other ages. Attention deficit hyperactivity disorder (ADHD) is a childhood disorder that can be diagnosed from early childhood. ${ }^{1}$ According to the statistical and diagnostic guide, there are three types of ADHD: predominantly hyperactive, predominantly inattentive, or combined. ${ }^{1}$ This is a heterogeneous behavioural neurological disorder with several possible causes, including genetic and environmental factors and, in fact, multiple factors, which can lead to change in neural pathway and may be associated with several disorders, ${ }^{2}$ and also has a significant economic impact on social health costs. ${ }^{3}$

The prevalence of all ADHD types was 12.12 per cent and 8.2 per cent among students studying at public nongovernment elementary schools in Tabriz-Iran, respectively. ${ }^{4}$ Although symptoms of ADHD starts before age 7 years, there is little information on the prevalence of ADHD amongst children aged less than 7 years due to the difficulty of collecting samples in the general population of elementary school children. ${ }^{5,6}$ Primarily, parents and then teachers are the most important individuals who establish the strongest relationship with these children; therefore, parents and kindergarten instructors and teachers of preschool centres are considered as the most important sources for the ADHD assessment at this age group specially for gathering information for better psychological and psychiatric evaluations; ${ }^{7}$ however, there is little agreement between the assessment of parents and the teachers concerning the diagnosis of ADHD symptoms. ${ }^{7,8}$ Therefore, simultaneous review of parents' and teacher's reports seems to be one of the ways to reduce the ADHD screening error, as they provide valuable information, which can be helpful for authentic diagnosis. A review study which was carried out on the previous studies, estimated ADHD prevalence in pre-school boys in Ahvaz-Iran using the Conners scale and the results showed that the prevalence rate was 24.06 per cent, 4.51 per cent, 17.29 per cent and 2.25 per cent based on the positive rating scale, parent form, only teacher questionnaire and both parent and teacher questionnaires. ${ }^{9}$ Moreover, a study was carried out on 1083 preschool children aged 5 and 6 years to estimate the prevalence of ADHD in Mashhad-Iran. Their result showed that 12.3 per cent of children suffer from ADHD and this was obtained after carrying out screening process using parent and teacher report using 10-items of Conners Index questionnaire and the Kiddie Schedule for Affective Disorders and Schizophrenia (K-SADS) clinical interview. ${ }^{5}$ The prevalence rate was 18.1 per cent and 6.7 per cent among boys and girls, respectively.

A study in Japan aimed to estimate the prevalence of ADHD symptoms in preschool children using a 14-item researchermade questionnaire and the results showed that the prevalence of ADHD was 31.1 per cent and 4.3 per cent based on the parent and teacher report questionnaires, respectively. According to both parents and teacher's reports, the prevalence of ADHD was higher in boys than girls, and the prevalence of ADHD decreases with age. ${ }^{10}$

Overall, the results of studies have estimated that the prevalence of ADHD in pre-school children range from 1.9 to 31.1 per cent. Moreover, the ADHD prevalence rate has been reported to be higher in boys than girls. ${ }^{1,5,9,11-13}$ Considering the differences between the parents' and teacher's report, it seems that investigating the prevalence of ADHD requires an examination of the results of both parents' and teacher's reports so that more accurate data can be obtained, as parents and teachers provide additional information separately and collectively, which can lead to better and accurate diagnosis. However, some studies indicated that there is no relation between parents' and teacher's report on ADHD assessment in preschool children. ${ }^{14}$ Considering the damages imposed on the children with ADHD, their families, as well as the subsequent economic losses, it is important and essential to design national and regional planning for managing ADHD. However, the best plan to cope and deal with the disease is to have a thorough knowledge of its prevalence at the societal level and to estimate the subsequent costs and damages. However, there has been no study on the prevalence of ADHD in children aged 3 to 6 years, 11 months in Tabriz and there is also little convergence between few available data obtained from other studies, in different part of Iran. Therefore, there is no accurate information in this regard. Accordingly, the question is: What percentage of children aged 3 years to 6 years, 11 months have ADHD in Tabriz? As a result, the following screening study was outlined to address this question in Tabriz, North West of Iran.

\section{Method}

This is a cross-sectional study. Study participants were 
children aged 36 months to 6 years, 11 months old selected from kindergarten and preschool centres in Tabriz, Iran. According to the available data, about 11,000 children and students attend 160 active kindergartens and preschool centres in Tabriz. Regardless of gender, 750 children and students were selected from 37 kindergartens and schools using a random cluster and consecutive sampling method. All samples were selected between June 1, 2015 and June 1, 2016. First, teachers completed the Conners Early Childhood Behaviour Scale-Teachers version (Conners Early Childhood BEH-T), then the parents completed the Conners Early Childhood Behaviour-Parent version (Conners Early Childhood BEH-P). Out of the selected subjects, 737 students for whom both the Conners Early Childhood Behaviour-Parent \& Conners Early Childhood BehaviourTeacher versions were completed participated in the study. The following three types of measurements were used to screen ADHD: 1. Diagnosis based on the cut-off point for the mean scores of the parents; 2 . Diagnosis based on the cutoff point for the mean scores of the teacher; 3 . Diagnosis based on the cut-off point of both parents' and teacher's report questionnaire.

\section{Inclusion and exclusion criteria}

The inclusion criteria included having parents'and teachers' consent over letting children to participate in the study, having at least reading and writing skills (intermediate level) for parents, being at least 3 years old (36 months of age) and not more than 6 years, 11 months of age. The exclusion criteria included children who had gone psychiatric treatment due to a mental disorder, students from special needs comprehensive school and those with incurable or hard-to-cure diseases and/or very severe physical disabilities and children for whom both versions of the Conners Early Childhood Behaviour questionnaire were not completed.

\section{Measurements demographic questionnaire}

This questionnaire asked questions about the child's age, gender, and parents' level of education and employment status. There were also questions about the child's medical and psychiatric history, and the presence of psychiatric treatment, hard-to-cure diseases and/or severe/very severe disorders (such as cardiovascular, pulmonary diseases, and severe neurological problems diagnosed by a physician and membership in rehabilitation centres such and supportive organizations).

\section{Conners early childhood behaviour parent \& teacher form} Conners Early Childhood Behaviour Scale was developed by Connors (2010). The parent and teacher forms consist of
115 and 116 items, respectively. The parent version consists of 10 sub-scales, but the teacher version has an additional subscale of sleep problems. Conners Early Childhood Behaviour consists of 3 impairment items. In this study, only the ADHD subscale was used. The ADHD subscale of the teacher and parent versions consists of 20 and 16 items that gives the total ADHD score. Item scoring is carried out in the form of a 4-point rating scale ( $0=$ Never to $3=$ Very high). ${ }^{14}$ Conners has confirmed its construct validity using factor analysis and the internal consistency and test-retest reliability of the teacher and parent versions has been reported through the Cronbach's alpha coefficient 0.76 $0.94,0.71-0.87$ and $0.90,0.88$, respectively. In this study, the internal consistency rate and test-retest reliability of the Persian version of Conners EC BEH-T (S) for ADHD were reported to be 0.91 and $I C C=0.89$, respectively. Moreover, the internal consistency and test-retest reliability of the Conners EC BEH-P for the ADHD were reported to be 0.76 and $I C C=0.76$, respectively. ${ }^{15}$ According to the findings of the pilot study, the cut-off points of 24 and 15 were used for the mean scores of the parent's and teacher's versions, respectively. Also, if the child was diagnosed with ADHD based on the cut-off point of both parent and teacher's versions, (s)he was diagnosed with ADHD from both parent's and teacher's report.

\section{Statistical methods}

All statistical analysis were carried out using SPSS ver.21. Descriptive statistical methods (frequency, percentage, mean, standard deviation) were used to determine the prevalence of ADHD. Also, non-parametric Fisher exact test and Chi-square test were applied to carry out statistical analysis. In this study, $p<0.05$ was considered as the significance level.

\section{Results}

A total of 737 children aged 3 years (36 months) to 6 years and 11 months were enrolled in the study. A total of 406 (55.1 per cent) and 331 (44.9 per cent) were girls and boys, respectively. The mean, minimum and maximum age of children's fathers was $39.26 \pm 5.55,24$ and 59 years, respectively. The mean, minimum and maximum maternal age was $34.03 \pm 4.44,23$ and 49 years, respectively. The majority of parents had a high school diploma and the majority of fathers and mothers were employees and housewives, respectively (Table 1).

Based on the cut-off point of 24 for Conners EC-Parent (Table 2), the prevalence of ADHD was 337 (45.7 per cent). The results of Fisher's exact test showed that female-male 
ratio of the ADHD prevalence rate was 166 girls (40.9 per cent) and 171 boys (51.7 per cent) $\left(X^{2}=8.53, p=0.004\right)$.

Based on the cut-off point of 15 for Conners EC-Teacher, the prevalence of ADHD was 416 (56.4 per cent). The results of Fischer's exact test showed that there was no difference between girls ( $n=217,53.4$ per cent) and boys $(n=199,60.1$ per cent) in terms of the ADHD prevalence rate $\left(X^{2}=3.30\right.$, $\mathrm{p}=0.07)$.

The prevalence of ADHD was 225 (30.5 per cent) based on the both parents' and teachers' reports. The results of Fisher's exact test showed that 108 girls (26.6 per cent) vs. 117 boys (25.4 per cent) suffered from ADHD $\left(X^{2}=6.57\right.$, $\mathrm{p}=0.013$ ) (Table 2).

There was no significant relationship between the age and prevalence of ADHD based on the parents' report and both parents and teacher's report. However, according to the teacher's report and Chi-square test, the frequency of ADHD diagnosis is reduced with an increase in the age of children $\left(X^{2}=25.36, d f=3, p<0.001\right)$ (Table 3$)$.

\section{Discussion}

The present research was carried out to diagnose and screen ADHD among children aged 3 years to 6 years, 11 months using the CECB-P and -T form. The results showed that the ADHD prevalence rate according to parents' report was 45.7 per cent and teachers' report was 56.4 per cent. According to the combined report of parents-teachers, the prevalence rate of ADHD was 30.5 per cent and the same prevalence rate was higher in boys than in girls in general. The results obtained from this study in comparison to similar studies in other parts of Iran shows some obvious variations. For example, the results of ADHD screening in Ahvaz-Iran showed the prevalence of ADHD was 17.2 per cent and 4.5 per cent based on the teacher and parent versions of the Conners ADHD rating scales, respectively. ${ }^{9}$ Their study was different from our research because we used reports consisting of different number of items for measuring ADHD as well as inclusion of children aged 5-6 years as the only statistical population. In another study in Iran, ADHD screening was performed on children aged 3-6 years using a researcher-made questionnaire on ADHD symptoms. The results showed that the ADHD prevalence rate was 25.8 per cent and 18 per cent according to the parents' and teacher's reports, respectively. The prevalence rate was 15.3 per cent and 32.4 per cent among girls and boys, respectively. ${ }^{16}$ Another study was conducted on a sample of children aged 5-6 years in north-eastern Iran and the ADHD screening was performed using a 19-item
Conners parent-teacher questionnaire. ${ }^{17}$ The results showed that the ADHD prevalence in males versus females and the total prevalence rate were 18.1 per cent, 6.7 per cent, and 12.3 per cent, respectively. ${ }^{17}$ Other survey was conducted on a sample of children aged 3-6 years in Japan using both researcher-made parent- and teacher- reported scales for ADHD, the prevalence of ADHD symptoms was reported to be 31.1 per cent in the parent report and 4.3 per cent in the teacher survey, with a prevalence ratio of $7.2 .^{10}$ The results of a previous study in Spain showed that the overall prevalence of ADHD in children aged 3-6 years, screened using the Early Childhood Inventory-4, was 10.3 per cent based on parents' reports (13.3 per cent in boys and 5.1 per cent in girls), 6.9 per cent based on teachers' reports (10 per cent in boys and 2.4 per cent in girls) and 5.1 per cent based on an interviewing method (5.8 per cent in boys and 1.1 per cent in girls). ${ }^{18}$

The findings of the present research showed a higher ADHD prevalence rate in boys than in girls which isconsistent with the findings of previous studies. ${ }^{10,15-18}$ However, the ADHD prevalence rate in the present study was higher than previous studies, ${ }^{5,9,15,17,18}$ but was consistent with Meysamie's research. ${ }^{16}$ The difference in findings of the present research and the previous ones can be attributed to geographical location and ADHD measurement tools, which may have caused these variations. On the other hand, it is also a possibility that the regional prevalence of ADHD in children 3 years to 6 years, 11 months in Tabriz is more than in other geographical locations. Therefore, we suggest to carry out a reassessment using a clinical interview after screening. Therefore, it is necessary to conduct clinical interviews in order to make an accurate assessment of the prevalence of ADHD in future studies.

The findings of this study have been achieved in a social sample and among preschool and kindergarten children in Tabriz-Northwest of Iran. The research tool used in this study can be considered as one of the research limitations. Therefore, it is recommended to carry a similar study using other ADHD screening tools and then clinical interviews for more accurate information.

\section{Conclusion}

The results obtained from this study suggest that ADHD is a common disorder among preschool and kindergarten children in such a way that about $1 / 3$ (30.5 per cent) of children aged 3 years to 6 years, 11 months from Tabriz suffer from this disorder. The ADHD prevalence rate was 35.4 per cent and 26.6 per cent among boys and girls, respectively. There was no difference between different age 
groups in terms of the ADHD prevalence rate. Although in contrast to previous studies, the present study revealed a significant difference in the prevalence of ADHD in different part of Iran; overall, the findings of this study emphasize the importance of ADHD screening in all kindergarten and preschool children for health interventions and promotion of social health.

\section{References}

1. American Psychiatric Association. Diagnostic and statistical manual of mental disorders. Text revision. 4th ed. Washington D.C: American psychiatric association press; 2000.

2. Gargaro BA, Rinehart NJ, Bradshaw JL, et al. Autism and ADHD: How far have we come in the comorbidity debate? Neurosci Biobehav Rev. 2011;35(5):1081-8.

3. Doshi JA, Hodgkins P, Kahle J, et al. Economic impact of childhood and adult attention-deficit/hyperactivity disorder in the United States. J Am Acad Child Adolesc Psychiatry. 2012;51(10):990-1002.e2. doi: 10.1016/j.jaac.2012.07.008.

4. Amiri $S$, Fakhari $A$, Maheri $M$, et al. Attention deficit/hyperactivity disorder in primary school children of Tabriz, North-West Iran. Paediatr Perinat Epidemiol. 2010;24:597-601.

5. Hebrani P, Abdolahian E, Behdani F, et al. The prevalence of attention deficit hyperactivity disorder in preschool-age children in Mashhad, North-East of Iran. Arch Iranian Med. 2007;10(2):147-151.

6. Wilens TE, Biederman J, Brown S, et al. Psychiatric comorbidity and functioning in clinically referred preschool children and school-age youths with ADHD. J Am Acad Child Adolesc Psychiatry. 2002;41:262-268.

7. Murray DW, Kollins SH, Hardy KK, et al. Parent versus teacher ratings of attention-deficit/hyperactivity disorder symptoms in the Preschoolers with AttentionDeficit/Hyperactivity Disorder Treatment Study (PATS). J Child Adolesc Psychopharmacol. 2007;17(5):605-20.

8. Tashakori A, Afkandeh R. Prevalence of ADHD symptoms among male preschoolers based on different informants in Ahvas City of Iran. ISRN Pediatr. 2011;2011:709653.

9. Alizadeh $\mathrm{H}$, Armion $\mathrm{E}$, Coolidge $\mathrm{FL}$, et al. The prevalence of attention-deficit/hyperactivity disorder among primary school students in an Iranian rural region. Psychology. 2015;6:263-268.

10. Soma Y, Nakamura K, Oyama M, et al. Prevalence of attention-deficit/hyperactivity disorder (ADHD) symptoms in preschool children: discrepancy between parent and teacher evaluations. Environ Health Prev Med. 2009;14:150-154. doi: 10.1007/s12199-008-00754.
11. Wichstrøm L, Berg-Nielsen TS, Angold A, et al. Prevalence of psychiatric disorders in preschoolers, J Child Psychol Psychiatry. 2011. doi: 10.1111/j.14697610.2011.02514.x.

12. Pineda D, Ardila A, Rosselli $M$, et al. Prevalence of attention-deficit/hyperactivity disorder symptoms in 4to 17-year-old children in the general population. J Abnorm Child Psychol. 1999;27:455-462.

13. Pineda DA, Lopera F, Palacio JD, et al. Prevalence estimations of attention-deficit/ hyperactivity disorder: differential diagnoses and comorbidities in a Colombian sample. International Journal of Neuroscience. 2003;113(91):49-71.

14. Sims DM, Lonigan CJ. Multi-method assessment of ADHD characteristics in preschool children: Relations between measures. Early Child Res Q. 2012;27(2):329-337.

15. Conners C. Conners Early Childhood, Canada: Toronto, Multi-Health System Inc, 2010.

16. Meysamie A, Fard MD, Mohammadi MR. Prevalence of attention-deficit/hyperactivity disorder symptoms in preschool-aged Iranian children. Iran J Pediatr. 2011;21(4):467-472.

17. Abdekhodaie Z, Tabatabaei SM, Gholizadeh M. The investigation of ADHD prevalence in kindergarten children in northeast Iran and a determination of the criterion validity of Conners' questionnaire via clinical interview. Res Dev Disabil. 2012;33(2):357-61. doi: 10.1016/j.ridd.2011.10.006.

18. Canals J, Morales-Hidalgo $P$, Jané $M$, et al. ADHD prevalence in Spanish preschoolers: Comorbidity, sociodemographic factors, and functional consequences. J Atten Disord. 2016;1-11. doi: 10.1177/1087054716638511.

\section{ACKNOWLEDGEMENTS}

The authors are indebted to all teachers and parents participating in this study.

\section{PEER REVIEW}

Not commissioned. Externally peer reviewed.

\section{CONFLICTS OF INTEREST}

The authors declare that they have no competing interests.

\section{FUNDING}

This study was funded by Research Centre of Psychiatry and Behavioural Sciences of Tabriz University of medical science. 


\section{ETHICS COMMITTEE APPROVAL}

This research protocol was approved by the ethics committee of Tabriz University of Medical sciences (code no. IR.TBZMED.REC.1395.422).

Table 1: Results of Chi-square test on level of education, employment status and marital status

\begin{tabular}{|l|l|l|l|}
\hline Characteristics & Groups & N & $\%$ \\
\hline \multirow{5}{*}{ Gender } & Girl & 406 & 55.1 \\
& Boy & 331 & 44.9 \\
\hline \multirow{5}{*}{ Father Education } & $3-3.12$ & 40 & 5.4 \\
& $4-4.12$ & 89 & 12.1 \\
& $5-5.12$ & 113 & 15.3 \\
& $6-6.11$ & 495 & 67.2 \\
\hline \multirow{5}{*}{ Mother Education } & Middle school & 128 & 17.4 \\
& Diploma & 220 & 29.9 \\
& Associate & 50 & 6.8 \\
& BA & 205 & 27.8 \\
& MA & 134 & 18.2 \\
\hline \multirow{5}{*}{ Mother occupation } & Middle school & 88 & 11.9 \\
& Diploma & 251 & 34.1 \\
& Associate & 81 & 11 \\
& BA & 258 & 35 \\
& MA & 59 & 8 \\
\hline \multirow{5}{*}{ Father occupation } & Unemployed & 10 & 1.4 \\
& Worker & 135 & 18.3 \\
& Eorking in governmental organizations & 292 & 39.6 \\
& Employee & 222 & 30.1 \\
& Employer & 13 & 1.8 \\
& Military service & 11 & 1.5 \\
& Retired & 54 & 7.3 \\
\hline & Self-employed & 500 & 67.8 \\
& Housewife & 116 & 15.7 \\
& Workinate organizations & 16.4 \\
\hline
\end{tabular}


Table 2: ADHD prevalence and gender and results of Fisher's exact test

\begin{tabular}{|l|l|l|l|l|l|l|}
\hline & \multirow{2}{*}{ Group } & \multirow{2}{*}{$\begin{array}{l}\text { Total N } \\
\text { (\%) }\end{array}$} & \multicolumn{2}{|c|}{ Gender N (\%) } & Chi- & \multirow{2}{*}{ Power } \\
\cline { 4 - 6 } & & Girl & Boy & Square & \\
\hline Conner's EC-Parent & Non ADHD & $400(54.3)$ & $240(59.1)$ & $160(48.3)$ & 8.53 & 0.004 \\
Form & ADHD & $337(45.7)$ & $166(40.9)$ & $171(51.7)$ & & \\
\hline Conner's EC-Teacher & Non ADHD & $321(43.6)$ & $189(46.6)$ & $132(39.9)$ & 3.3 & 0.07 \\
Form & ADHD & $416(56.4)$ & $217(53.4)$ & $199(60.1)$ & & \\
\hline \multirow{2}{*}{ Both Parent \& Teacher Diagnosis } & Non ADHD & $512(69.5)$ & $298(73.4)$ & $214(64.7)$ & 6.57 & 0.013 \\
& ADHD & $225(30.5)$ & $108(26.6)$ & $117(35.4)$ & & \\
\hline
\end{tabular}

Table 3: ADHD Prevalence in age groups and results of Chi-Square

\begin{tabular}{|c|c|c|c|c|c|}
\hline & \multirow[b]{2}{*}{ Years old } & \multicolumn{2}{|c|}{ ADHD N (\%) } & \multirow[b]{2}{*}{ Chi-Square } & \multirow[b]{2}{*}{ Power } \\
\hline & & $\begin{array}{l}\text { Non } \\
\text { ADHD }\end{array}$ & ADHD & & \\
\hline \multirow{4}{*}{$\begin{array}{l}\text { Conner's EC-Parent } \\
\text { Form }\end{array}$} & 3 to 3.11 & $20(50)$ & $20(50)$ & \multirow[t]{4}{*}{2.16} & \multirow[t]{4}{*}{0.53} \\
\hline & 4 to 4.11 & $54(60.7)$ & $35(39.3)$ & & \\
\hline & 5 to 5.11 & $58(51.3)$ & $55(48.7)$ & & \\
\hline & 6 to 6.11 & $268(54.1)$ & $227(45.9)$ & & \\
\hline \multirow{4}{*}{$\begin{array}{l}\text { Conner's EC-Teacher } \\
\text { Form }\end{array}$} & 3 to 3.11 & $9(22.5)$ & $31(77.5)$ & \multirow[t]{4}{*}{25.36} & \multirow[t]{4}{*}{$<0.001$} \\
\hline & 4 to 4.11 & $22(24.7)$ & $67(75.3)$ & & \\
\hline & 5 to 5.11 & $49(43.4)$ & $64(56.6)$ & & \\
\hline & 6 to 6.11 & 241(48.7) & $254(51.3)$ & & \\
\hline \multirow{4}{*}{ Both Parent \& Teacher Diagnosis } & 3 to 3.11 & $24(60)$ & $16(40)$ & \multirow[t]{4}{*}{2.86} & \multirow[t]{4}{*}{0.41} \\
\hline & 4 to 4.11 & $61(68.5)$ & $28(31.5)$ & & \\
\hline & 5 to 5.11 & $75(66.4)$ & $38(33.6)$ & & \\
\hline & 6 to 6.11 & $352(71.1)$ & $143(28.9)$ & & \\
\hline
\end{tabular}

